\title{
LA ESCUELA AUSTRIACA
}

\author{
JESÚS HUERTA DE SOTO*
}

«Lo que distingue a la Escuela Austriaca y habrá de proporcionarle fama inmortal es precisamente el hecho de haber desarrollado una teoría de la acción económica y no de la "no acción" o "equilibrio" económico.»

(VON Mises, 2001: 70)

La Escuela Austriaca es una escuela de economistas de gran abolengo que ha experimentado un notable resurgir en los últimos treinta años y que actualmente se postula como una de las principales alternativas de futuro para sustituir al paradigma neoclásico-walrasiano hasta ahora dominante en la Ciencia Económica, pero que hoy ha entrado en una fase de estancamiento por el gran irrealismo de sus supuestos, su carácter estático y reduccionismo formal. Por el contrario, la Escuela Austriaca centra su programa de investigación en el análisis de los procesos dinámicos de cooperación social que caracterizan al mercado, dando especial relevancia al papel protagonista que juega en los mismos la función empresarial y las diferentes instituciones que hacen posible la vida en sociedad. En agudo contraste con las diferentes versiones del análisis económico que considera que el mercado se encuentra en un equilibrio aquejado

(*) Jesús Huerta de Soto es Catedrático de Economía Política en la Universidad Rey Juan Carlos, Madrid. 
de fallos (neo y post Keynesianos), o carente de ellos por ser pareto-eficiente (Escuela de Chicago), los cultivadores de la Escuela Austriaca consideran que ambas versiones del análisis del equilibrio, a pesar de su oposición ideológica, adolecen de la misma incomprensión sobre el funcionamiento real del mercado, entendido como un proceso empresarial de creatividad y coordinación que, por definición, nunca puede alcanzar ningún óptimo de tipo paretiano, pero que es dinámicamente eficiente (en el sentido de que impulsa la creatividad y la coordinación) siempre que la coacción institucional del estado (intervencionismo y socialismo) no dificulten el ejercicio de la función empresarial y la libre apropiación de los frutos de su acción creadora (respeto a la propiedad privada en el marco de un estado de derecho con un gobierno de poderes limitados).

Entre los principales éxitos teóricos y aportaciones de la Escuela Austriaca al avance de la humanidad destaca la demostración científica de la imposibilidad de organizar la sociedad en base a mandatos y reglamentos coactivos (socialismo e intervencionismo) pues no es posible que el órgano regulador o planificador se haga con la información de primera mano que necesita para dar un contenido coordinador a sus mandatos, por lo que los economistas de la escuela austriaca fueron los únicos en prever el desmoronamiento de las economías de socialismo real y la crisis sin salida del estado del bienestar. Esta predicción contrasta con la incapacidad de los teóricos del equilibrio general (Lange, Taylor, Samuelson, Dickinson y otros) para ni siquiera apreciar el problema insoluble de cálculo económico que plantea el socialismo, pues en sus modelos se parte de suponer que toda la información necesaria para solucionar el correspondiente sistema de ecuaciones "ya está dada», y podría ser conocida por el planificador en todo momento, por lo que consideran resuelto $a b$ initio el problema real que el orden espontáneo del mercado resuelve cada día en un entorno de continuo cambio, creatividad y coordinación. Tampoco los teóricos 
del equilibrio de la Escuela de Chicago (Knight, Friedman, Stigler, Rosen, Coase) pudieron entender en su plenitud el desafío de la Escuela Austriaca al paradigma dominante. Así, Sherwin Rosen ha terminado reconociendo que «el colapso de la planificación central fue una sorpresa para la mayoría de nosotros» (Rosen, 1997: 139-152). Y el propio Ronald H. Coase ha admitido que «nada de lo que había leído o sabía sugería que el colapso del sistema socialista iba a ocurrir» (Coase, 1997: 45).

Otra aportación muy importante de la Escuela Austriaca es su teoría del capital, del dinero y de los ciclos económicos. Según esta teoría, la concesión expansiva de créditos sin respaldo de un aumento efectivo del ahorro voluntario a que da lugar el sistema de banca privilegiada para operar con un coeficiente de reserva fraccionaria, actualmente en vigor en todo el mundo bajo la supervisión de los bancos centrales en un entorno de dinero nacionalizado y leyes de curso forzoso, inexorablemente induce de forma recurrente un «alargamiento» ficticio e insostenible de los procesos de inversión productiva (burbuja especulativa que genera graves errores de inversión reales), que de esta forma tienden a hacerse desproporcionadamente intensivos en capital. La amplificación del proceso inflacionario mediante la expansión crediticia, de manera espontánea e inexorable, habrá de revertirse, dando lugar a una crisis o recesión económica en la que los errores de inversión se pondrán de manifiesto y surgirá el desempleo y la necesidad de liquidar y reasignar los recursos erróneamente invertidos. Las crisis, por tanto, no son exógenas como creen los teóricos de Chicago y de los «shocks externos» (Kydland y Prescott), ni consustanciales a la economía de mercado (como piensan los Keynesianos y el resto de los teóricos de los fallos del mercado), sino que surgen por un problema de erróneo diseño institucional (la existencia de una banca con reserva fraccionaria) que se solucionaría con la privatización del dinero (patrón-oro puro), la exigencia de un coeficiente de caja del 100 por cien 
para los depósitos a la vista (como en cualquier otro depósito de bien fungible, trigo o aceite por ejemplo), y la eliminación de los bancos centrales (únicos órganos de planificación socialista en el ámbito monetario que aún quedan en vigor en las economías modernas). No es de extrañar, por tanto, que los teóricos austriacos (Ludwig von Mises y Friedrich A. Hayek) fueran los únicos en predecir el advenimiento de la Gran Depresión de 1929 (cuando el propio Keynes y los monetaristas encabezados por Fisher consideraban que se había entrado en una etapa nueva e irreversible de bonanza económica), como resultado de los desmanes monetarios y financieros cometidos tras la fundación de la Reserva Federal en 1913 y, especialmente, en los «felices años veinte» del siglo pasado. E igualmente predijeron la recesión inflacionaria que se desencadenó a partir de la mal llamada crisis del petróleo en 1973, y que dio al traste con el análisis teórico Keynesiano; así como los reiterados avisos que vienen dando tras los doce años de burbuja crediticia y «exuberancia irracional» que han caracterizado al periodo de la denominada «nueva» Economía que va desde 1992 hasta hoy (2004) (Véase Huerta de Soto, 2005).

Otras aportaciones de gran interés de la Escuela Austriaca son el desarrollo de la teoría de la función empresarial, entendida como la capacidad del ser humano para darse cuenta de las oportunidades de ganancia subjetiva que surgen en el entorno, actuando en consecuencia para aprovecharse de las mismas, y generando así un proceso inagotable de creatividad y coordinación de desajustes previos que constituye el corazón del orden espontáneo del mercado (Hayek, Kirzner). Intimamente relacionado con lo anterior está el concepto dinámico de competencia entendida como un proceso de creatividad y descubrimiento en el que los empresarios rivalizan unos con otros para detectar y aprovechar antes que los demás las oportunidades de ganancia, concepto que se encuentra en las antípodas del modelo neoclásico de competencia «perfecta» en el que, 
paradójicamente, todos hacen lo mismo y venden al mismo precio, es decir, en el que nadie compite. Igualmente destaca la crítica a la indebida aplicación del método de las ciencias naturales y la física al campo de la economía («cientismo» en la terminología hayekiana), así como el desarrollo de una metodología apriorístico-deductiva que relaciona adecuadamente el mundo de la teoría (formal) con el de la historia (empírica). El uso de las matemáticas en economía es rechazado por tratarse de un lenguaje formal que ha surgido a instancias de las necesidades de la ciencia física y de la lógica formal, en las que se dan el presupuesto de constancia y en las que la creatividad empresarial y el transcurso del tiempo subjetivo (no «espacializado») brillan por su ausencia: solamente el lenguaje verbal creado evolutivamente por los seres humanos en su diario quehacer empresarial se considera adecuado para el análisis científico de las realidades de órdenes espontáneos propios del mercado que nunca están en equilibrio. Además, los economistas austriacos consideran que el campo de la predicción específica es empresarial y no corresponde al científico de la economía que, como mucho, tan sólo podrá efectuar «predicciones» de tipo cualitativo o teóricas («pattern predictions») referentes a los efectos descoordinadores del intervencionismo económico en cualquiera de sus facetas pero sin que los economistas puedan efectuar como científicos de la economía predicciones aplicables a unas coordenadas de tiempo y lugar determinados. En suma, el problema económico fundamental para los economistas de la Escuela Austriaca no es de naturaleza técnica ni de maximización de una función objetivo «conocida» y constante sometida a restricciones también «conocidas» y constantes, sino que, por el contrario, es estrictamente «económico» (en el sentido austriaco): surge cuando los fines y los medios son muchos, compiten entre sí, el conocimiento en cuanto a los mismos no está dado ni es constante, sino que se encuentra disperso en las mentes de innumerables seres humanos que 
continuamente lo están creando y generando ex novo y, por tanto, ni siquiera se puedan conocer todas las posibilidades alternativas existentes, ni las que se vayan a crear en el futuro, ni la intensidad relativa con que se quiere perseguir cada una de ellas. Por todo ello, no es de extrañar que importantes economistas neoclásicos, como Mark Blaug, hayan sido valientes y finalmente hayan declarado su apostasía del modelo de equilibrio general y de la síntesis neoclásica-Keynesiana concluyendo que «de forma lenta y extremadamente reacia he llegado a darme cuenta de que los teóricos de la Escuela Austriaca estaban en lo cierto y de que todos los demás hemos estado equivocados» (Blaug y De Marchi, 1991: 508). Para los teóricos austriacos es especialmente errónea la defensa del mercado libre de la Escuela de Chicago: un mercado «perfecto» en términos neoclásicos es una contradicción en los términos, y el mercado debe defenderse no por ser eficiente en términos paretianos sino porque es un proceso de descubrimiento, creatividad y coordinación que jamás está en equilibrio y además carece de alternativas, no pudiendo mejorarse (sino todo lo contrario) mediante la regulación intervencionista del estado.

Aunque existe un acuerdo generalizado en que la Escuela Austriaca nace en 1871 con la publicación del libro de Carl Menger (1840-1921) Principios de Economía Política, en realidad este autor recoge una tradición del pensamiento de la Europa Continental que se remonta a los estudios de los teóricos españoles de la Escuela de Salamanca (siglos XVI-XVII), por lo que, stricto sensu, la Escuela Austriaca debería denominarse «Escuela Española» (Huerta de Soto, 2000). Así, nuestros escolásticos del Siglo de Oro articularon los siguientes principios básicos de la Escuela Austriaca: primero, la teoría subjetiva del valor (Diego de Covarrubias y Leyva); segundo, el descubrimiento de que son los precios los que determinan los costes y no al revés (Luis Saravia de la Calle); tercero, la naturaleza dinámica del mercado y la imposibilidad de alcanzar y conocer los datos del 
equilibrio (Juan de Lugo y Juan de Salas); cuarto, el concepto dinámico de competencia, entendida como un proceso de rivalidad entre vendedores (Castillo de Bovadilla y Luis de Molina); quinto, el redescubrimiento del principio de la preferencia temporal (Martín de Azpilcueta); sexto, el carácter distorsionador de la inflación sobre la economía real (Juan de Mariana, Diego de Covarrubias y Martín de Azpilcueta); séptimo, el análisis crítico de la banca ejercida con reserva fraccionaria (Luis Saravía de la Calle y Martín de Azpilcueta); octavo, el descubrimiento de que los depósitos bancarios forman parte de la oferta monetaria (Luis de Molina y Juan de Lugo); noveno, la imposibilidad de organizar la sociedad mediante mandatos coactivos por falta de información (Juan de Mariana); y décimo, la tradición liberal de que toda intervención injustificada sobre el mercado viola el derecho natural (Juan de Mariana).

Las principales aportaciones de Menger (teoría subjetiva del valor, utilidad marginal, teoría del surgimiento espontáneo de las instituciones, concepción del proceso de producción como una serie de etapas sucesivas y crítica al historicismo en la Methodenstreit contra Schmoller), fueron desarrolladas por su alumno más brillante, Eugen von Böhm-Bawerk (1851-1914), que las aplicó a la teoría del interés (determinado por la valoración subjetiva de la preferencia temporal y nunca por la productividad marginal del capital) y a la teoría del capital (entendido como el valor estimado a precios de mercado libre de los bienes de capital que encarnan las etapas intermedias de todo proceso productivo). Böhm-Bawerk demolió además la teoría marxista de la explotación y la teoría de Marshall sobre la mutua determinación de los precios (en base a la utilidad - correctoy a los costes - erróneo-). La tercera generación de economistas austriacos está encabezada por Ludwig von Mises (18811973), sin duda alguna el más importante de todos ellos y al que se deben las aportaciones prácticas más trascendentales de la Escuela (teoría de la imposibilidad del socialismo, teoría 
del ciclo económico, teoría de la función empresarial, crítica del intervencionismo, y sistematizacion metodológica) y el tratado de economía austriaca más conocido La acción humana publicado en múltiples ediciones en todos los idiomas. El principal discípulo de Mises fue Friedrich A. Hayek (1899-1992), premio Nobel de economía en 1974, que profundizó en todas las aportaciones de Mises, demolió la teoría económica Keynesiana y fue el principal teórico del orden espontáneo del mercado durante el siglo XX. Ya en nuestros días, los principales economistas austriacos han sido Murray N. Rothbard (1926-1995), autor de más de veinte libros y centenares de artículos de teoría e historia y principal impulsor de la teoría del anarco-capitalismo; e Israel M. Kirzner (1930-), catedrático de economía de la Universidad de Nueva York, que ha refinado al máximo la teoría austriaca de la función empresarial. Una pléyade de jóvenes teóricos y profesores de universidades de Europa y América están dedicando sus esfuerzos a profundizar y avanzar en las aportaciones de la Escuela Austriaca y publican sus trabajos en múltiples revistas científicas entre las que destacan The Quaterly Journal of Austrian Economics, publicada por el Ludwig von Mises Institute de la Universidad de Auburn, The Review of Austrian Economics publicada por Kluwer, la francesa Journal des Economistes et des Etudes Humaines, y la española Procesos de Mercado: Revista europea de economía política.

\section{BIBLIOGRAFÍA BÁSICA}

HayeK, Friedrich A.: Huerta de Soto, J. (ed.), Unión Editorial, Madrid 1997. La fatal arrogancia: los errores del socialismo, Vol. I de las Obras Completas de F.A. Hayek.

Huerta De Soto, Jesús: Editorial Síntesis, Madrid 2000. La Escuela Austriaca: mercado y creatividad empresarial. Unión Editorial, Madrid 2001. Socialismo, cálculo económico y función empresarial, 2. ${ }^{a}$ edición. 
KIRZNER, Israel M.: Unión Editorial, Madrid 1998. Competencia y empresarialidad.

Mises, Ludwig von: Unión Editorial, Madrid 2004. La acción humana: tratado de economía, $7 .^{\text {a }}$ edición.

Rothbard, Murray N.: The Scholars' Edition, Ludwig von Mises Institute, Auburn University, Alabama 2004. Man, Economy, and State. Unión Editorial, Madrid 1999-2000. Historia del Pensamiento Económico, Vols. I y II.

\section{REFERENCIAS CITADAS EN EL TEXTO}

BlaUg, Mark y Marchi, N. de (eds.): Edward Elgar, Londres 1991. Appraising Economic Theories.

Coase, Ronald H.: Reason, Junio 1987. «Looking for Results». Huerta de Soto, Jesús: Unión Editorial, Madrid 2005. Dinero, crédito bancario y ciclos económicos, 3. ${ }^{a}$ edición.

Mises, Ludwig von: Unión Editorial, Madrid 2001. Autobiografía de un liberal.

Rosen, Sherwin: Journal of Economic Perspectivas, Vol. II, n. ${ }^{\circ}$, 1997, pp. 139-152, «Austrian and Neoclassical Economics: Any Gains from Trade?». 